\title{
Technological relatedness: How do firms diversify their technology?
}

\author{
Seung Hwan Kim ${ }^{\mathrm{a}, *}$, Bogang Jun ${ }^{\mathrm{b}, \mathrm{c}, 1, *}$, Jeong-Dong Lee ${ }^{\mathrm{a}, *}$ \\ ${ }^{a}$ Technology Management, Economics and Policy Program, Seoul National University, Seoul, South Korea \\ ${ }^{b}$ Department of Economics, Inha University, Incheon, South Korea \\ ${ }^{c}$ Department of Data Science, Inha University, Incheon, South Korea
}

\begin{abstract}
The principle of relatedness, which helps estimate the affinity between economic activities, suggests that cities, regions, and countries are more likely to undertake new economic activities when they already perform related activities. This empirical principle has been confirmed for various dimensions - cities, regions, and countries—and their activities- developing new technologies, products, and industries. However, the technological diversification of firms is yet unexplored. Is a firm more successful at entering a new technology when it has already accumulated related technologies? Here, we explore this issue using a unique dataset that contains firms' patent data and financial and market information. In particular, we examine Korean firms listed in the Korean stock market that published patents at the patent offices in Korea, Europe, and the United States from 1984 to 2004. We develop a technological relatedness measure to estimate whether a firm has already published patents with similar technologies. We find that firms are more likely to develop a new technology when they already have related technologies. Interestingly, technological relatedness shows an increasing return to related knowledge. We also check the robustness of this effect using propensity score matching and find that the effects of technological relatedness and its increasing return behavior remain significant when controlling for potential confounding effects. These findings extend the concept of relatedness to a firm's technological diversification and show that the development of a firm's technological knowledge is shaped by its technological relatedness.
\end{abstract}

Keywords: Economic Complexity, Patent data, Knowledge Accumulation Strategy of Firm, Relatedness

\section{Introduction}

The principle of relatedness indicates that cities, regions, and countries are more likely to undertake new economic activities such as those related to new technologies, new products, and new industries when they already conduct related activities (Hidalgo et al., 2018; Hidalgo, 2021). In their seminal work, Hidalgo et al. (2007) found that the probability of a country exporting a new product increases when it already exports related products. Jun et al. (2017) expanded the

${ }^{*}$ Email address: bogang.jun@inha.ac.kr 
research to international bilateral trade, finding that the probability of successfully exporting a new product to a destination is likely to increase when a firm already exports related products to that destination.

The principle holds at the regional level as well. Neffke et al.(2011) found that new industries in Sweden are more likely to be developed in certain regions when those regions house related industries. Jara-Figueroa et al. (2018) showed that the industrial diversification of regions in Brazil is more successful when a new firm, which initially introduced the new industry to the region, has relevant industry-specific knowledge. Further, Gao et al. (2017) showed that a new industry is more likely to emerge in Chinese provinces that already house related industries.

At the city level, Kogler et al. (2013) and Rigby (2015) analyzed US patent data and found that cities are more likely to expand their technological territory to technologies related to the those they already own. Consequently, the technological specialization of US cities rises over time. Similarly, Boschma et al. (2014) showed that the entry probability of a new technology at the US city level increases with its level of relatedness with existing technologies. Furthermore, relatedness matters not only for the technological specialization of a city but also for its occupational specialization. Examining labor market data in the United States, Muneepeerakul et al. (2013) found that the current occupational specialization of urban areas shapes their future occupational specialization. New occupations that appear in the area are more likely to be related to existing occupations in that area.

This empirical principle has been supported by growing evidence describing the entry of technologies, products, industries, and occupations at the international, national, regional, and city scales. However, empirical evidence of technological relatedness at the firm level is scarce. Although Kogler et al. (2013), Rigby (2015), Boschma et al. (2014), and Balland et al. (2019) examine technological relatedness, their unit of analysis is mostly the city and region, based on the aggregation of patent data.

Here, we contribute to this literature on the principle of relatedness by using 30 years (19842014) of patent data at the firm level including 408,426 patents, 880 firms, and 122 technologies. Focusing on Korean manufacturing firms that are listed in the Korean stock market, we construct a unique unbalanced panel dataset that combines patents and their financial information through the disambiguation of patent's applicant and the firm name on the financial information. Next, following the method of Hidalgo et al. (2007), we develop a technological relatedness measure, termed density, to estimate whether a firm has previously published patents with similar technologies. The results using this large patent dataset confirms that firms are more likely to develop a new technology when they already have related technologies. Interestingly, technological relatedness shows an increasing return to related knowledge. We also check the robustness of this effect using propensity score matching (PSM) and find that the effects of technological relatedness and its increasing return behavior remain significant when controlling for potential confounding effects. These findings extend the concept of relatedness to a firm's technological diversification and show that the development of a firm's technological knowledge is shaped by its technological relatedness.

\section{Literature review: Technological diversification of firms}

Nelson and Winter (1982) insisted that the development of firms and nations is the learning process accompanying the cumulative capabilities embedded in the networks of individuals and firms. In this stream of the literature, capabilities represent the explicit and tacit knowledge embodied in routines and procedures, which makes the learning process deeply path- 
dependent (Polanyi, 1958, Collins, 2010). The ability of a firm to accumulate these capabilities depends, among other factors, on the institutional environment in which it is located (Saxenian, 1996), the firm's organizational structure (Powell 1990$)$, the dynamic capability of the firm to learn (Teece and Pisano, 1994), the social networks in which the economy is embedded (Granovetter 1985), and, especially, the related firms and neighboring regions that have already accumulated the right capabilities.

Scholarly efforts have pushed the ideas of learning not only focusing on the factors that affect learning, but also on the learning channels at various levels including country, region, and firm. At the country level, Hidalgo et al. (2007) used export data to show that the probability of a country developing a comparative advantage on a new product depends on the number of related products that it already exports. In this seminal work, Hidalgo et al. (2007) introduced the idea of the product space, which is a network connecting the products that countries are likely to co-export. Using the product space, a measure of product relatedness, called density, can be calculated. This product relatedness measure can capture the score of each product that a country does not yet export by examining the number of related products that it already exports. Hidalgo et al. (2007) found that this relatedness measure works well as a predictor of the probability of a country successfully developing a comparative advantage on a new product in the future.

At the regional level, scholars have examined data on labor flows, the input-output relationship, and the location of firms to measure related knowledge that the region can access to undertake new economic activities (Jara-Figueroa et al., 2018; Gao et al., 2017; Boschma, 2017, Delgado et al. 2016, Boschma et al. |2012:| Boschma and Iammarino, 2009: Frenken et al. 2007). Neffke et al. (2011) used regional data on the product portfolios of manufacturing plants to connect industries and create the product space of Sweden. This research showed that the number of related industries in the region affects the probability of it successfully welcoming new industries. Jara-Figueroa et al. (2018) used data on individuals' work history in the Brazilian labor market, connected industries by examining labor flows across industries, and drew the industry space of Brazil. Developing three kinds of density measures, which are the density of industry-specific, occupation-specific, and location-specific knowledge, they showed that related knowledge in a new industry that already exists in a region plays the most significant role in the industrial diversification of that region. Gao et al. (2017) also showed that Chinese provinces are more likely to enter a new industry when they already house related industries. Gao et al. (2017) used data on Chinese firms listed in the Chinese stock market and, examining the locations of these firms, connected industries and generated the Chinese industry space. Those studies used factory-level and firm-level data, but they aggregated these data to understand the industrial diversification of regions.

At the firm level, Teece $(1980,1982)$ explained the product diversification of multi-product firms. Teece (1980) argued that multi-product firms, which produce a diverse portfolio of related products, choose an efficient way to organize economic activities when the development of products requires reusing proprietary know-how and specialized physical assets. Later, Teece (1982) showed that considering the fungible and tacit characteristics of organizational knowledge, profit-seeking firms are likely to diversify to avoid the high transaction costs associated with using various markets to trade services and specialized assets. Furthermore, Teece et al. (1994) explored why firms diversify coherently. Using US firm-level data in 1987, they found that firms expanding by adding related activities are the most common type of firms in the United States.

While Teece (1980, 1982) and Teece et al. (1994) have examined firms' product diversification strategies in depth, some research has investigated the technological diversification of firms. 
Jaffe (1986) was the first to introduce a measure of a firm's technological distance by examining its patents. To characterize the technological position of the firm, Jaffe used the distribution of firms' patents by patent class and defined the cosine similarity index that represents the change in the distribution over time. He found evidence that firms' patents, along with their profit and market value, are systematically related to the technological position of their research programs and that they even move in the technology space in response to the pattern of contemporaneous profits in different positions. Breschi et al.(2003) also studied the technological diversification of a firm by introducing technological relatedness, focusing on the development of its core technology. They calculated the cosine similarity index by examining the co-occurrence of International Patent Classification (IPC) codes in every patent and found that knowledge relatedness, which is measured using the cosine similarity index, is a key factor in firms' technological diversification. However, thus far, research on firms' technological diversification has not adopted the density measure that accounts for the accumulation of all the related technologies of the firm rather than its representative technology.

\section{Data}

We use two datasets in our analysis, namely, publicly listed firm data from National Information \& Credit Evaluation Inc. (NICE) and the European Patent Office Worldwide Patent Statistical Database (PATSTATS), both covering 1984 to 2014. We analyze manufacturing firms listed in Korea's three major stock markets 1 and their patents published by either the Korean Intellectual Patent Office (KIPO), the European Patent Office (EPO) or the United States Patent and Trademark Office (USPTO). Firms' technology-related information is from the PATSTATS dataset, while their financial information is derived from the stock market datasets. One may argue that our data capture only large companies. However, considering that most $R \& D$ activities are carried out by large listed companies, which accounted for three-quarters of the total R\&D investment in Korea in 2014 (Bae 2016)), the analysis of listed companies represents knowledge accumulation by Korean companies well.

The publicly listed firm data from NICE have provided financial information on companies subject to external auditing in Korea as a KIS-value database since 1985 2 The data include information related to the initial public offering (e.g., listing date, de-listing date, and tenure) and general financial information (e.g., number of workers, sales, and total assets). Qualitative information related to the stability of the financial structure such as the debt ratio and profit ratio can be calculated based on the given financial information.

The global PATSTATS dataset is created by the EPO on request from the OECD (Kang and Tarasconi, 2016). PATSTATS is updated twice a year and we use the Autumn 2017 edition. Since PATSTATS covers data from more than $90 \%$ of the world's patent authorities including the KIPO, EPO and USPTO, we can access the patents in the KIPO, EPO and USPTO using the PATSTATS dataset. The data contain comprehensive information on each patent including

\footnotetext{
${ }^{1}$ The Korean stock market can be roughly divided into two types. The first type is the Korea Composite Stock Price Index that targets large companies. The second type targets small and medium-sized enterprises (SMEs), including the Korea Securities Dealers Automated Quotation, which focuses on promising SMEs based on advanced technology, and Korea New Exchange, a stock market for SMEs with lower listing thresholds. This study targets the manufacturing companies listed in the above three markets.

${ }^{2}$ Although the KIS-value database was launched in 1985, it provides financial information on firms from 1980.
} 
applicants, inventors, publications, citations, filing country, filing date, registration status, and IPC codes.

Using both the patent and the financial data, we first match the patents from the PATSTATS dataset based on the applicant's information. However, the applicant's information is not the unique identifier in the patent data. Even for the same applicant, there could be variations in the written name for reasons such as spelling errors, abbreviations, the use of a non-unified company name, and a change of company name. For this reason, the process of matching a company-owned patent with a company owner is not always accurate. Accordingly, Hall et al. (2001), He et al. (2018), Julius and De Rassenfosse (2014), and Thoma et al. (2007) have aimed to standardize the names of applicants, with Kim et al. (2016), Lee et al. (2019), and Kang et al. (2019) focusing on Korean firms. This study uses the OECD Harmonised Applicants' Names (HAN) database, which is based on text-matching algorithms such as the one presented by Kang et al. (2019). The HAN database provides a unique firm identifier called the HAN-ID that harmonizes the names of applicants in different countries. However, there are still mismatches and errors in OECD HAN, and no changes in company name are considered (Kang et al., 2019). This study therefore unifies both mismatches in the HAN ID and errors in applicants' names to obtain the name of the representative applicant.

Next, this representative applicant's name is matched with the KIS-value that provides financial information. As a result, we can construct a unique unbalanced panel dataset of listed Korean manufacturing companies.

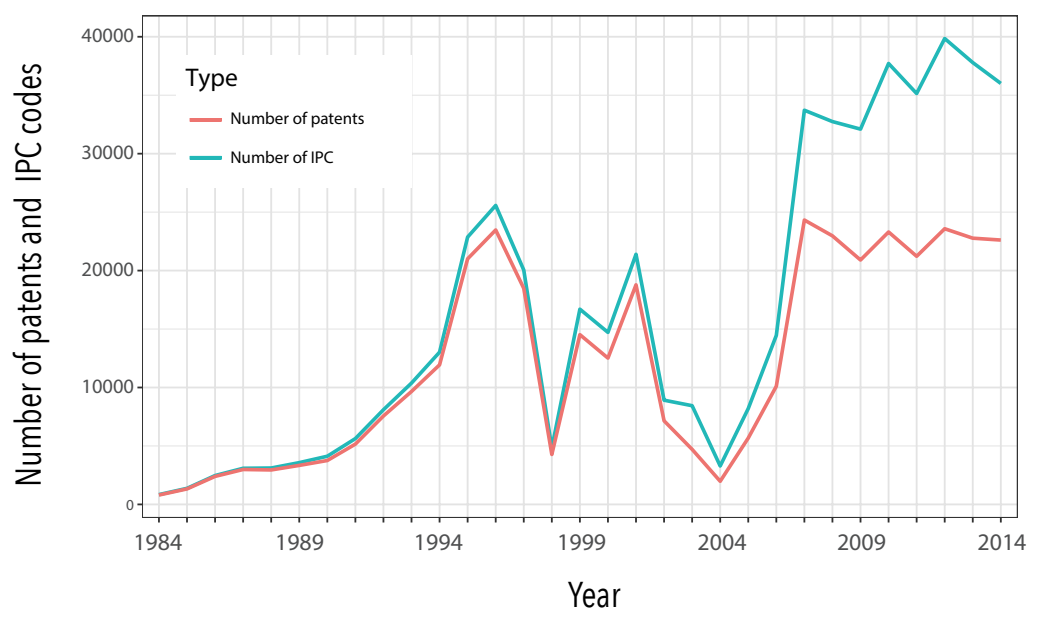

Figure 1: Numbers of patents and Number of IPC codes after the disambiguation, Data source: PATSTATS dataset

We analyze the data in three periods: 1984-1997, 1998-2003, and 2004-2014. Figure (1) depicts the numbers of patents and IPC codes in the combined dataset, where the IPC code of a patent is used as a proxy of its technology. It shows that the numbers of patents and IPC codes move in the same direction and that the number of the latter is slightly higher than that of the 
former because each patent should have at least one IPC code. From 2007, the difference between the numbers of IPC codes and patents expands, as international patent applications become more active. In addition, we observe two inflection points in both lines, in 1998 and 2004. In the late 1990s, Korea suffered from the Asian financial crisis and needed financial relief from the International Monetary Fund. Many firms suddenly failed and declared bankruptcy, leading to vast unemployment. The dotcom bubble in the early 2000s quickly followed. Without time for recovery, many IT-related firms faced bankruptcy once again. As a result, the number of patent applications started to drop dramatically from 2000, reaching the lowest value since 1985 in 2004. By contrast, the global financial crisis in 2008 did not affect patenting activity, as shown in Figure (1). Of the three periods of data, we choose the most recent one as our main dataset.

\section{Empirical strategy}

\subsection{Measuring technological relatedness}

Does a firm's probability of successfully entering a new technology increase when it already has related technologies? To answer this question, we introduce a measure of relatedness and use it to estimate the proportion of related technologies already existing in the firm (Hidalgo et al. 2007, Kogler et al. 2013, Boschma et al., 2014, Gao et al., 2017, Jun et al., 2017).

First, we connect the IPC codes of each patent and firm by building an IPC code-firm bipartite network in which the weight of the link is the number of IPC codes possessed by the firm. (Again, the IPC code is used as a proxy of technology.) Every patent requires one or more IPC codes to classify its technology. We examine all the IPC codes written in one patent instead of using the representative IPC code. For example, if firm $i$ obtains a patent applied for or granted at time $t$, whose IPC codes are A, B, and C according to the KIPO, we regard this case as the company having developed all three technologies at time $t$. In the case of a family of patents, although the patent is identical, a new IPC code (e.g., technology D) could be added following the request of an examiner when filing the patent at another patent office (e.g., USPTO). After considering a patent granted by the KIPO or USPTO as one family patent, all non-overlapping technology areas (IPC codes A-D) are synthesized and regarded as the technology of the corresponding patent.

Figure 2 (A) shows the technology space of Korea based on patent data from 1984 to 2014 (see the Appendix A for details of the visualization methods). Each node represents a technological category, while the links represent the proximity between technologies. The technology space of Korea exhibits a core/periphery structure such that the subcategories of physics and mechanical engineering, lighting, heating, and weapons are likely to be located in the center, while those of human necessities, textiles, and paper are at the periphery. Simultaneously, we can observe a coherent cluster in the upper left-hand corner, which consists of the subcategories of electricity, physics and mechanical engineering, lighting, heating, and weapons. This cluster is from Samsung, which owns 31\% of all Korean patents and specializes as an electronics and chip maker (see Table 5 for the results when Samsung is excluded from the sample).

Next, using this network, we calculate the proximity by examining the co-occurrence of the IPC codes of the patents of the same firm and then estimate the proximity $\left(\phi_{\alpha, \beta}\right)$ between technologies $\alpha$ and $\beta$ following the method of Hidalgo et al. (2007) The proximity indicates the

\footnotetext{
${ }^{3}$ When we calculate the proximity $\phi_{\alpha, \beta, t}$, we aggregate the patents for five years from year $t$ since the highest backward citation is achieved by patents published for fewer than five years (Hall et al. 2001), and technology $\alpha$ at time $t$ is developed based on the background knowledge accumulated from time $t-5$ to time $t$
} 
(A)

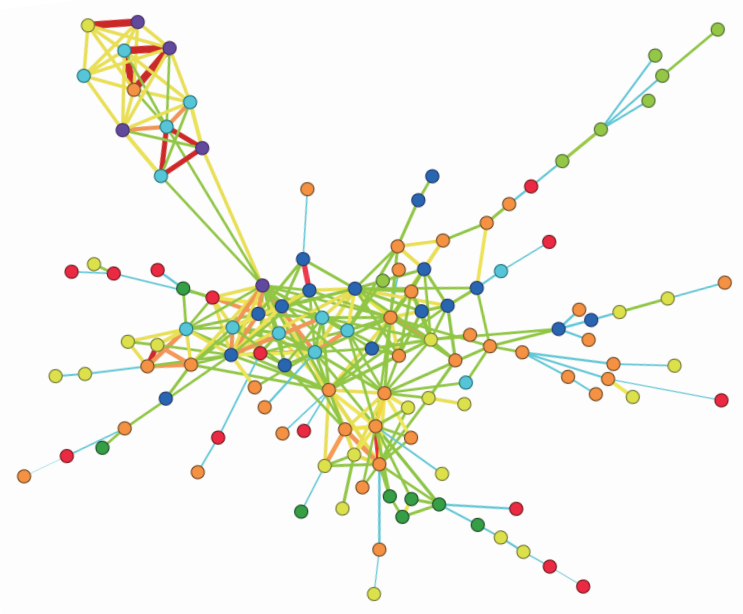

Link Weight (proximity)

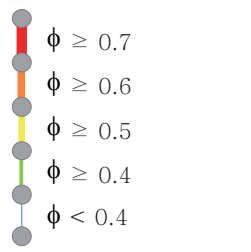

Node Color (IPC category)

A: Human Necessities

B: Performing Operations, Transporting

C: Chemistry, Metallurgy

D: Textiles, Paper

E: Fixed Constructions

F: Mechanical Engineering, Lighting, Heating, Weapons

G: Physics

H: Electricity
(B) Samsung 1986

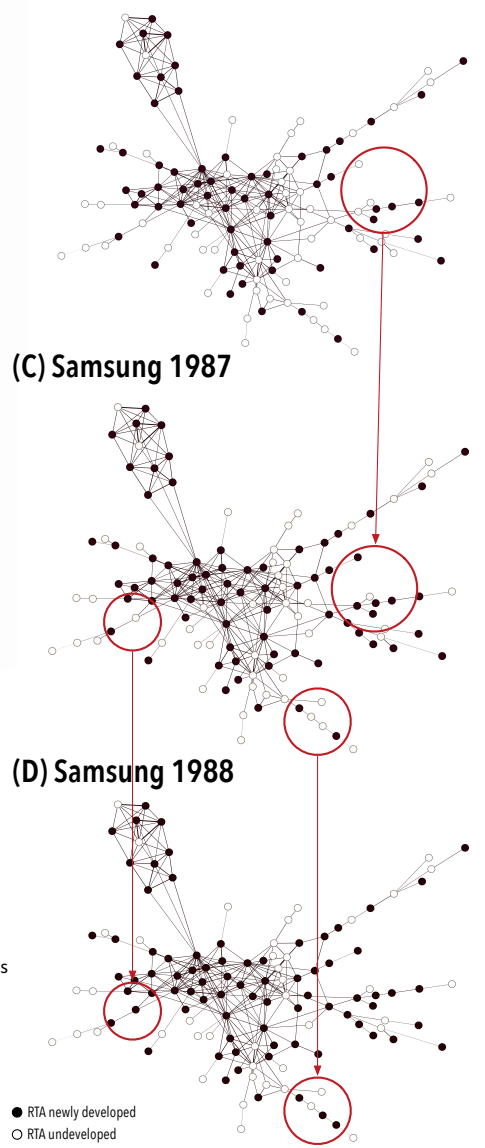

Figure 2: (A) Technology space and (B)-(D) The development of the technology of Samsung

minimum value of the pairwise conditional probability that two technologies have a comparative advantage together within the same firm:

$$
\phi_{\alpha, \beta}=\min \left\{\operatorname{Pr}\left(R T A_{\alpha} \mid R T A_{\beta}\right), \operatorname{Pr}\left(R T A_{\beta} \mid R T A_{\alpha}\right)\right\}
$$

where RTA represents the revealed technological advantage:

$$
R T A_{i, \alpha, t}=\frac{\frac{P_{i, \alpha, t}}{\sum_{\alpha} P_{i, \alpha, t}}}{\frac{\sum_{\alpha} P_{i, \alpha, t}}{\sum_{i} \sum_{\alpha} P_{i, \alpha, t}}}
$$

where $P_{i, \alpha, t}$ is the number of patents related to technology $\alpha$ possessed by firm $i$ at time $t$ (Balassa 1965).

RTA indicates the comparative advantage of firm $i$ in technology $\alpha$ by measuring whether it owns more technology $\alpha$, as a share of its total technologies, than the average firm. We state 
(A)

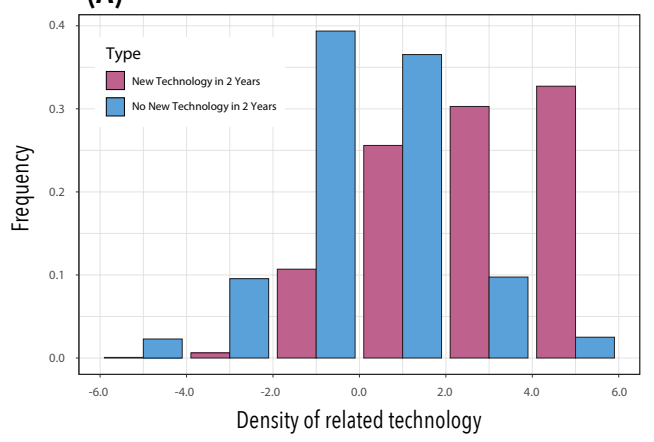

(B)

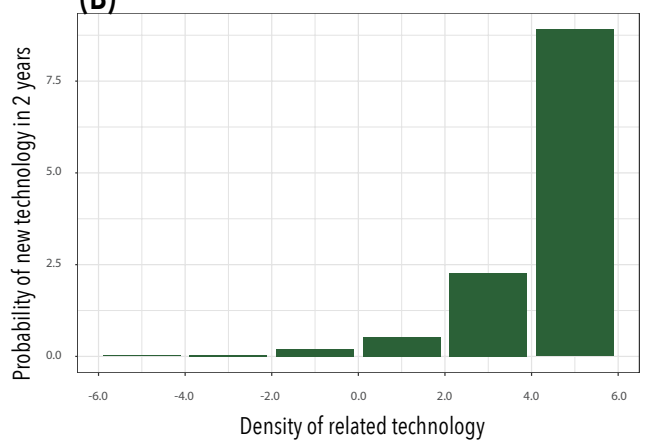

Figure 3: Fig:density

that firm $i$ develops a comparative advantage in technology $\alpha$ at time $t$ when its $R T A_{i, \alpha, t}$ has a transition from $R T A_{i, \alpha}<1$ to $R T A_{i, \alpha} \geq 1$. Considering that previously developed technologies require some time (often more than three years) to affect the next generation of new related technologies, we examine the three years before the development of a new technology. When we define the firm's development of a new technology $\alpha$ at time $t$, it has the technology whose RTA value is below 1 at time $t-1$, over 1 at time $t$, and holds its value over 1 at time $t+1$ and time $t+2$ considering forward condition (Bahar et al., 2014).

Lastly, using the proximity among technologies, we aggregate the related technologies of a firm, which we term the density of the related technology of firm $i\left(\omega_{i, \alpha, t}\right)$. Formally, the density of the related technology for technology $\alpha$ of firm $i$ at time $t$ is given by

$$
\omega_{i, \alpha, t}=\frac{\sum_{\beta} \phi_{\alpha, \beta, t} U_{i, \beta, t}}{\sum_{\beta} \phi_{\alpha, \beta, t}}
$$

where $\phi_{\alpha, \beta, t}$ is the proximity between technology $\alpha$ and $\beta$ and $U_{i, \beta, t}$ takes 1 if firm $i$ has an RTA in technology $\beta$ in year $t\left(R T A_{i, \beta, t} \geq 1\right)$ and 0 otherwise.

Figure 3 (A) shows the frequency of the densities for the technologies that a firm entered (in pink) or did not enter (in blue) within a two-year period. The distribution shows that the density is larger for the technologies that firms enter than for those they do not. Interestingly, the frequency of the densities for entering new technologies (in pink) increases over the density range. Figure 3 (B) shows the probability of a firm entering a new technology as a function of the density of related technologies. This increasing and convex relationship between the density and probability of entering a new technology indicates that the probability of a firm entering a new technology increases strongly with the relatedness density, implying the path-dependent characteristics of technological diversification.

The path-dependent pattern of technological diversification can also be observed in Figures 2 (B)-(D), which depict the technologies of Samsung in 1986-1988. The black dots indicate that Samsung has a comparative advantage in that technology, while the circle means no comparative advantage. As shown in the figure, new technology is likely to appear when the circle is surrounded by black dots (Alshamsi et al. 2018). 


\subsection{Econometric model}

Table 1: Summary statistics (year 1984-2014)

\begin{tabular}{lccccc}
\hline \hline Statistic & No. of obs. & Mean & St. Dev. & Min & Max \\
\hline$U_{i, \alpha, t+2}$ & 733,894 & 0.007 & 0.086 & 0 & 1 \\
$\omega_{i, \alpha, t}$ & 733,894 & 0.000 & 1.889 & -5.739 & 5.973 \\
Industry $_{\alpha, t}$ & 733,894 & 0.000 & 0.287 & -0.530 & 0.722 \\
Age $_{i, t}$ & 733,894 & 0.000 & 2.420 & -6.339 & 8.142 \\
Sales $_{i, t}$ & 733,894 & 0.000 & 3.126 & -25.184 & 13.209 \\
Profit $_{i, t}$ & 733,894 & 0.000 & 30.201 & -344.090 & 150.933 \\
Debt $_{i, t}$ & 733,894 & 0.000 & 0.473 & -2.555 & 8.644 \\
\hline \hline
\end{tabular}

We use a multivariate probit model to estimate the probability of a firm entering a new industry as a function of the density of its related technologies. Our econometric model is

$$
\begin{aligned}
U_{i, \alpha, t+2} & =\beta_{0}+\beta_{1} \omega_{i, \alpha, t}+\beta_{2} \omega_{i, \alpha, t}^{2} \\
& +\beta_{3} \text { Industry }_{\alpha, t}+\beta_{4} \text { Age }_{i, t}+\beta_{5} \text { Sales }_{i, t} \\
& +\beta_{6} \text { Profit }_{i, t}+\beta_{7} \text { Debt }_{i, t} \\
& +\theta_{t}+\mu_{i}+\varepsilon_{i, \alpha, t}
\end{aligned}
$$

where $U_{i, \alpha, t}$ takes 1 when firm $i$ has a comparative advantage in technology $\alpha$ at time $t$ and 0 otherwise. Our main explanatory variable $\omega_{i, \alpha, t}$ again represents the density of related technologies. We also add the square term of $\omega_{i, \alpha, t}$ to check whether an increasing return to technological density exists. The next line includes a variable that represents the firm's technological environment, that is Industry I $_{\text {. }}$. This variable is the number of firms that have a comparative advantage in technology $\alpha$ in the industry to which the firm belongs. This variable captures two aspects: how many learning opportunities exist in the industry and how many competitors for that technology exist in the industry. We also control for the characteristics of the firm. Age $e_{i, t}$ is the tenure of firm $i$ (i.e., from its inception to year $t$ ). Sales $s_{i, t}$ allows us to control for the size effect of the firm, while Profit $t_{i, t}$ and $D e b t_{i, t}$, which are the ratio of profit to sales and the ratio of total liabilities to total assets in year $t$, respectively, allow us to control for the quantitative aspects of the firm (representing its capital structure). These variables for the firm's capital structure can capture its value and expected growth. Finally, we add year-fixed effects $\left(\theta_{t}\right)$ and industry-fixed effects $\left(\mu_{i}\right)$ to control for the nationwide time trend and time-invariant characteristics of industries, respectively. $\varepsilon_{i, \alpha, t}$ is the error term and all the variables, except the dependent variable $U_{i, \alpha, t}$, are transformed by Box-Cox transformation to satisfy normality. Table 1 presents the summary statistics of our dataset covering 1984 to 2014 and the correlation table is in the Appendix B Table A1. Since the correlation coefficient between Age $_{i, t}$ and $S$ ales $s_{i, t}$ is insufficiently low, we check the variance inflation factor for all the pairwise variables, finding that no pair of variables has a value higher than 2. The results of the variance inflation factor test of $A g e_{i, t}$ and ales $_{i, t}$ are 1.405 and 1.711 , respectively ( 1.421 and 1.669 when we only consider the main results from 2004 to 2014). Therefore, we use all the covariables together. 


\section{Results}

\subsection{Firms' technological diversification among related technologies}

\begin{tabular}{lcccc}
\hline \hline & \multicolumn{4}{c}{ Dependent variable: $\mathrm{U}_{i, \alpha, t+2}$} \\
\cline { 2 - 5 } & $(1)$ & $(2)$ & $(3)$ & $(4)$ \\
\hline$\omega_{i, \alpha, t}$ & $0.25^{* * *}$ & $0.21^{* * *}$ & $0.17^{* * *}$ & $0.17^{* * *}$ \\
$\omega_{i, \alpha, t}^{2}$ & $(0.01)$ & $(0.01)$ & $(0.01)$ & $(0.01)$ \\
& & $0.01^{* * *}$ & $0.01^{* * *}$ & $0.01^{* * *}$ \\
Industry $_{\alpha, t}$ & & $(0.00)$ & $(0.00)$ & $(0.00)$ \\
& & & $1.09^{* * *}$ & $1.09^{* * *}$ \\
Age $_{i, t}$ & & & $(0.04)$ & $(0.04)$ \\
& & & -0.00 & -0.00 \\
Sales $_{i, t}$ & & & $(0.01)$ & $(0.01)$ \\
Profit $_{i, t}$ & & & $0.04^{* * *}$ & $0.04^{* * *}$ \\
& & & $(0.00)$ & $(0.00)$ \\
Debt & & & & $0.00^{*}$ \\
& & & & $(0.00)$ \\
& & & & $-0.06^{*}$ \\
Log Likelihood & -13422.53 & -13405.88 & -12850.42 & -12843.05 \\
Deviance & 26845.06 & 26811.77 & 25700.83 & 25686.10 \\
No. of obs. & 351824 & 351824 & 351824 & 351824 \\
\hline \hline
\end{tabular}

${ }^{* * *} p<0.001 ;{ }^{* *} p<0.01 ;{ }^{*} p<0.05$

Table 2: Firms' technological diversification among related technologies after two years, 2004-2014.

Table 2 shows our main results from 2004 to 2014 . We see that $\omega_{i, \alpha, t}$, which represents technological relatedness, has a positive and significant effect on the probability of a firm entering a new technology after two years. The effect of technological relatedness holds with the covariates, which control for the industrial environment, firm age, sales, the profit share, and the debt ratio. This result means that the probability of a firm successfully entering a new technology increases with its accumulation of related technologies. Since the coefficient of $\omega_{i, \alpha, t}$ is approximately 0.17 , a 10 percentage point increase in $\omega_{i, \alpha, t}$ results in a 0.63 percentage point increase in the dependent variable, keeping all the other variables at their mean.

As shown in columns (1)-(4), the square term of omega consistently has a positive and significant effect. This implies that an increasing return to technological densities exists. Since the coefficient of $\omega_{i, \alpha, t}$ is positive, the vertices of the quadratic functions have a negative sign, meaning that the effect has an increasing return to density monotonically without a minimum point. In addition, the significant and positive effects of Industry $y_{i, t}$ in columns (3) and (4) indicate that firms are more likely to enter a new technology when more firms that already have the same technology belong to their industry. The number of other firms that already have the technology can be translated in two ways: the competition effect and learning effect. If other firms already have the new technology, the focal firm can have more opportunities to learn about it. Further, the 
fact that other firms have the new technology indicates that the environmental and institutional characteristics of the new technology (e.g., academic theory and human capital) are already part of the economy. Simultaneously, the level of Industry int $_{\text {can }}$ capresent the degree of competition in the industry. If other firms already have the same technology, the firm developing the new technology loses its monopolistic position with the new patent. Since our results show a positive coefficient, the learning effect is dominant for Korean firms. As shown in Table 2, Age $e_{i, t} i, t$ does not have a significant effect on the technological diversification of firms. The result implies that getting older does not guarantee that firms' knowledge will expand by default. Lastly, Sales $s_{i, t}$ and Profit $t_{i, t}$ have clear positive effects on knowledge diversification, while $D e b t_{i, t}$ does not show a significant effect.

\begin{tabular}{|c|c|c|c|}
\hline & \multicolumn{3}{|c|}{ Dependent variable: $U_{i, \alpha, t+2}$} \\
\hline & 1984-1997 & $1998-2003$ & 2004-2014 \\
\hline \multirow[t]{2}{*}{$\omega_{i, \alpha, t}$} & $0.13^{* * *}$ & $0.18^{* * *}$ & $0.17^{* * *}$ \\
\hline & $(0.01)$ & $(0.02)$ & $(0.01)$ \\
\hline \multirow{2}{*}{$\omega_{i, \alpha, t}^{2}$} & $0.01^{* * *}$ & 0.00 & $0.01^{* * *}$ \\
\hline & $(0.00)$ & $(0.00)$ & $(0.00)$ \\
\hline \multirow[t]{2}{*}{ Industry $_{\alpha, t}$} & $1.43^{* * *}$ & $1.23^{* * *}$ & $1.09^{* * *}$ \\
\hline & $(0.05)$ & $(0.07)$ & $(0.04)$ \\
\hline \multirow[t]{2}{*}{$\mathrm{Age}_{i, t}$} & $-0.02^{*}$ & -0.00 & -0.00 \\
\hline & $(0.01)$ & $(0.01)$ & $(0.01)$ \\
\hline \multirow{2}{*}{ Sales $_{i, t}$} & $0.12^{* * *}$ & $0.05^{* * *}$ & $0.04^{* * *}$ \\
\hline & $(0.01)$ & $(0.01)$ & $(0.00)$ \\
\hline \multirow[t]{2}{*}{ Profit $_{i, t}$} & $0.00^{* * *}$ & 0.00 & $0.00^{*}$ \\
\hline & $(0.00)$ & $(0.00)$ & $(0.00)$ \\
\hline \multirow[t]{2}{*}{ Debt $_{i, t}$} & 0.01 & -0.01 & $-0.06^{*}$ \\
\hline & $(0.07)$ & $(0.05)$ & $(0.02)$ \\
\hline Log Likelihood & -7856.66 & -3604.65 & -12843.05 \\
\hline Deviance & 15713.31 & 7209.31 & 25686.10 \\
\hline No. of obs. & 158541 & 164441 & 351824 \\
\hline
\end{tabular}

${ }^{* * *} p<0.001 ;{ }^{* *} p<0.01 ;{ }^{*} p<0.05$

Table 3: Firms' technological diversification among related technologies after two years by periods

Table 3 presents the results by subperiod. As noted earlier, from 1998 to 2003, the Korean economy underwent a structural change owing to help from the International Monetary Fund Structural Adjustment Programs. The years between the Asian financial crisis and dotcom bubble (1998-2003) were an extremely unstable transition period in which a considerable number of firms went bankrupt and the core technology of Korea shifted from precision machinery and automobiles to computers, semiconductors, and IT. As a consequence, all three periods show results similar to our main results in Table 2 but the increasing return to density disappears during this period of turmoil.

To check whether the effect of technological relatedness varies by $R \& D$ intensity and $R \& D$ costs, we divide the sample by $R \& D$ intensity (i.e., total $R \& D$ costs at the industry level over total 
sales at the industry level) and R\&D costs. We categorize the International Standard Industry Code (ISIC) Rev. 4 codes based on R\&D intensity and R\&D costs and classify them as low, medium, and high intensity/costs. The results in Table 4 show that the coefficient of technological relatedness is the highest for industries with low $\mathrm{R} \& \mathrm{D}$ intensity and low $\mathrm{R} \& \mathrm{D}$ costs, implying that those sectors with low $R \& D$ pressure are more likely to pick low-hanging fruit. Interestingly, those industries with high $R \& D$ pressure are more likely to utilize the increase return to the technological density.

\begin{tabular}{|c|c|c|c|c|c|c|}
\hline & \multicolumn{5}{|c|}{ Dependent variable: $U_{i, \alpha, t+2}$} & \\
\hline & \multicolumn{3}{|c|}{ R\&D Intensity } & \multicolumn{3}{|c|}{ R\&D Costs } \\
\hline & Low & Medium & High & Low & Medium & High \\
\hline \multirow[t]{2}{*}{$\omega_{i, \alpha, t}$} & $0.19^{* * *}$ & $0.15^{* * *}$ & $0.15^{* * *}$ & $0.17^{* * *}$ & $0.16^{* * *}$ & $0.16^{* * *}$ \\
\hline & $(0.01)$ & $(0.01)$ & $(0.01)$ & $(0.02)$ & $(0.01)$ & $(0.01)$ \\
\hline \multirow{2}{*}{$\omega_{i, \alpha, t}^{2}$} & 0.00 & $0.01^{*}$ & $0.02^{* * *}$ & $0.02^{* * *}$ & 0.01 & $0.02^{* * *}$ \\
\hline & $(0.00)$ & $(0.00)$ & $(0.00)$ & $(0.00)$ & $(0.00)$ & $(0.00)$ \\
\hline \multirow[t]{2}{*}{ Industry $_{\alpha, t}$} & $1.32^{* * *}$ & $1.17^{* * *}$ & $1.19^{* * *}$ & $1.10^{* * *}$ & $1.17^{* * *}$ & $1.25^{* * *}$ \\
\hline & $(0.07)$ & $(0.04)$ & $(0.04)$ & $(0.07)$ & $(0.05)$ & $(0.04)$ \\
\hline \multirow{2}{*}{$\operatorname{Age}_{i, t}$} & -0.01 & -0.00 & $-0.02^{*}$ & -0.00 & -0.00 & $-0.01^{*}$ \\
\hline & $(0.01)$ & $(0.01)$ & $(0.01)$ & $(0.01)$ & $(0.01)$ & $(0.01)$ \\
\hline \multirow[t]{2}{*}{ Sales $_{i, t}$} & $0.02^{*}$ & $0.08^{* * *}$ & $0.06^{* * *}$ & $0.03^{*}$ & $0.07^{* * *}$ & $0.05^{* * *}$ \\
\hline & $(0.01)$ & $(0.01)$ & $(0.00)$ & $(0.01)$ & $(0.01)$ & $(0.00)$ \\
\hline \multirow[t]{2}{*}{ Profit $_{i, t}$} & 0.00 & 0.00 & $0.00^{* * *}$ & -0.00 & $0.00^{*}$ & $0.00^{* * *}$ \\
\hline & $(0.00)$ & $(0.00)$ & $(0.00)$ & $(0.00)$ & $(0.00)$ & $(0.00)$ \\
\hline \multirow[t]{2}{*}{ Debt $_{i, t}$} & -0.07 & 0.02 & -0.05 & $0.18^{* *}$ & $-0.10^{* *}$ & $-0.05^{*}$ \\
\hline & $(0.04)$ & $(0.03)$ & $(0.03)$ & $(0.06)$ & $(0.04)$ & $(0.02)$ \\
\hline Log Likelihood & -4164.75 & -8690.41 & -11745.36 & -3326.08 & -7192.59 & -13987.18 \\
\hline Deviance & 8329.50 & 17380.82 & 23490.71 & 6652.16 & 14385.17 & 27974.36 \\
\hline No. of obs. & 198731 & 245882 & 276723 & 95423 & 238923 & 386990 \\
\hline
\end{tabular}

${ }^{* * * *} p<0.001 ;{ }^{* *} p<0.01 ;{ }^{*} p<0.05$

Table 4: Firms' technological diversification among related technologies after two years by R\&D intensity and costs

Since the Korean market and its industries are controlled by large industrial conglomerates called chaebols, one might argue that the technology space is also determined by their behavior. Indeed, of all the patents granted by the KIPO and applied for or granted by the USPTO, Samsung's patents account for $30.96 \%$ compared with $57.29 \%$ for the four largest firms ${ }^{4}$. To isolate the effect of these large conglomerates, we divide our sample into two subsamples. The first subsample includes the four major companies based on number of patents (Samsung, LG, Hyundai, and Posco) and the second comprises the remainder of the firms. Table 5 shows the results. The effect of technological relatedness once again holds for the major companies and, interestingly, the effect is larger than that for the other companies. Simultaneously, the increasing return to density disappears for large firms. This result implies that they are likely to prioritize low-hanging

\footnotetext{
${ }^{4}$ Samsung's number of patents is 126,454 compared with 233,996 for the four major companies, which are Samsung, LG, Hyundai, and Posco. The number of Korean patents granted by the KIPO and applied for or granted by the USPTO is 408,426 .
} 


\begin{tabular}{|c|c|c|}
\hline & \multicolumn{2}{|c|}{ Dependent variable: $U_{i, \alpha, t+2}$} \\
\hline & Four major companies & Others \\
\hline \multirow[t]{2}{*}{$\omega_{i, \alpha, t}$} & $0.28^{*}$ & $0.16^{* * *}$ \\
\hline & $(0.13)$ & $(0.01)$ \\
\hline \multirow{2}{*}{$\omega_{i, \alpha, t}^{2}$} & 0.02 & $0.01^{* * *}$ \\
\hline & $(0.02)$ & $(0.00)$ \\
\hline \multirow[t]{2}{*}{ Industry $_{\alpha, t}$} & $1.66^{* * *}$ & $1.17^{* * *}$ \\
\hline & $(0.11)$ & $(0.03)$ \\
\hline \multirow[t]{2}{*}{$\operatorname{Age}_{i, t}$} & 0.10 & -0.00 \\
\hline & $(0.13)$ & $(0.00)$ \\
\hline \multirow[t]{2}{*}{ Sales $_{i, t}$} & $-0.13^{*}$ & $0.06^{* * *}$ \\
\hline & $(0.06)$ & $(0.00)$ \\
\hline \multirow[t]{2}{*}{ Profit $_{i, t}$} & $-0.01^{*}$ & $0.00^{* * *}$ \\
\hline & $(0.00)$ & $(0.00)$ \\
\hline \multirow[t]{2}{*}{ Debt $_{i, t}$} & $-0.99^{* * *}$ & -0.02 \\
\hline & $(0.28)$ & $(0.02)$ \\
\hline Log Likelihood & -2045.86 & -22635.84 \\
\hline Deviance & 4091.72 & 45271.67 \\
\hline No. of obs. & 6134 & 717741 \\
\hline
\end{tabular}

${ }^{* * *} p<0.001 ;{ }^{* *} p<0.01 ;{ }^{*} p<0.05$

Table 5: Firms' technological diversification among related technologies after two years of the four major firms (Samsung, LG, Hyundai, and Posco) and others

fruit using their established technological infrastructure. Simultaneously, they attempt to explore new technological territory (i.e., they do not remain with their specialty).

\subsection{Robustness check: Propensity score matching}

To check the robustness of our results, we generate the control group using PSM, a widely used method that aims to reduce the confounding effects of other variables. PSM requires researchers to create treatment and control groups. In our case, the treatment group consists of firms whose technological relatedness is sufficiently high and the control group comprises the remainder. After the Box-Cox transformation, we allocate the value 1 to when the density is over 0 and 0 otherwise. The two matched groups should have similar covariates except for the treated variable. Then, we calculate the propensity of having high technological density using the following equation:

$$
\text { treated }_{i, \alpha, t}=\beta_{0}+\beta_{1} \text { Industry }_{\alpha, t}+\beta_{2} \text { Age }_{i, t}+\beta_{3} \text { Sales }_{i, t}+\beta_{4} \text { Profit }_{i, t}+\beta_{5} \text { Debt }_{i, t}+\varepsilon_{i, \alpha, t}
$$

where treated $_{i, \alpha, t}$ is a binary variable that represents technological relatedness. Again, Industry $y_{\alpha, t}$ is the number of firms that have a comparative advantage in technology $\alpha$ in the industry to which the firm belongs, $A g e_{i, t}$ is the tenure of firm $i$ (i.e., from its inception to year $t$ ), Sales $s_{i, t}$ is the 


\begin{tabular}{lccc}
\hline \hline & \multicolumn{3}{c}{ Dependent variable: $U_{i, \alpha, t+2}$} \\
\cline { 2 - 4 } & $(1)$ & $(2)$ & $(3)$ \\
\hline$\omega_{i, \alpha, t}$ & $0.20^{* * *}$ & $0.17^{* * *}$ & $0.17^{* * *}$ \\
$\omega_{i, \alpha, t}^{2}$ & $(0.01)$ & $(0.01)$ & $(0.01)$ \\
& $0.01^{* * *}$ & $0.01^{* * *}$ & $0.01^{* * *}$ \\
Industry $_{\alpha, t}$ & $(0.00)$ & $(0.00)$ & $(0.00)$ \\
& & $1.09^{* * *}$ & $1.09^{* * *}$ \\
Age $_{i, t}$ & & $(0.04)$ & $(0.04)$ \\
Sales $_{i, t}$ & & -0.00 & -0.00 \\
& & $(0.01)$ & $(0.01)$ \\
Profit $_{i, t}$ & & $0.04^{* * *}$ & $0.04^{* * *}$ \\
Debt $_{i, t}$ & & $(0.00)$ & $(0.00)$ \\
& & & $0.00^{*}$ \\
Log Likelihood $_{\text {Deviance }}$ & & & $(0.00)$ \\
No. of obs. & & -13379.69 & $-0.05^{*}$ \\
\hline \hline
\end{tabular}

${ }^{* * *} p<0.001 ;{ }^{* *} p<0.01 ;{ }^{*} p<0.05$

Table 6: PSM results: Firms' technological diversification among related technologies after two years

firm's sales at time $t$, Prof $i t_{i, t}$ is the ratio of profit to sales, and $D e b t_{i, t}$ is the ratio of total liabilities to total assets in year $t . \varepsilon_{i, \alpha, t}$ is the error term.

To select the treatment and control groups from our data from 2004 to 2014, we choose the nearest neighbor algorithm, a popular method of classifying unclassified data into existing classes. The matched data have fewer observations than before (dropping from 351,824 to $342,121)$. Table 6 shows the results of the multivariate probit model. The effect of technological relatedness remains significant and positive and the increasing return to density is also still significant. These results confirm that firms are more likely to enter a new technology when they already have related technologies.

\section{Discussion and Conclusion}

Since Teece (1980, 1982) explained firms' product diversification behavior, ideas on firms' product and technology diversification have shaped our understanding of their dynamic strategy. To examine the dynamics of a firm's technologies, Jaffe (1986) was the first to measure the technological distance of the firm by examining its patents. Breschi et al. (2003) also studied the technological diversification of a firm using the cosine similarity index. In this study, we add another explanation of a firm's technological diversification to this strand of research using a density measure to represent technological relatedness. While the proximity or similarity index only captures the distance between technologies, our density measure focuses on all the related 
technologies that a firm has developed, thereby allowing us to describe the path-dependent characteristics of each firm comprehensively.

Our technological relatedness measure has been widely used in the fields of economic geography and economic complexity since the seminal work by Hidalgo et al. (2007). This stream of the literature states that cities, regions, and countries are more likely to undertake new economic activities such as new technologies, new products, and new industries when they already carry out related activities (Hidalgo et al. 2018, Hidalgo, 2021). While this empirical principle has been supported by rising evidence of the entry of technologies, products, industries, and occupations at the international, national, regional, and city scales, empirical evidence of technological relatedness at the firm level is scant. Although Kogler et al. (2013), Rigby (2015), Boschma et al. (2014), and Balland et al. (2019) examine technological relatedness, their unit of analysis is mostly the city and region, based on the aggregation of patent data.

Here, we contribute to two streams of the literature: a firm's technological diversification and the principle of relatedness using our technological relatedness measure. We use 30 years (19842014) of patent data on Korean manufacturing firms including 408,426 patents, 880 firms, and 122 technologies and construct a unique unbalanced panel dataset that combines their patents and financial information. Next, we calculate the technological relatedness measure, termed a firm's density, to estimate whether it has already published patents with the related technologies, following Hidalgo et al. (2007). We find that firms are more likely to develop a new technology when they already have related technologies. Interestingly, technological relatedness shows an increasing return to related knowledge. We also check the robustness of this effect using PSM and find that the effects of technological relatedness and its increasing return remain significant when controlling for potential confounding effects.

This study has one main limitation that can be addressed in future research. The proximity of different technologies is calculated using Korean firms' patents and associated applicant information. Thus, the results could lack generalizability beyond Korea. Future research should therefore consider the global level of proximity. Nonetheless, these findings extend the concept of relatedness to a firm's technological diversification and show that the development of its technological knowledge is shaped by its technological relatedness.

\section{Acknowledgement}

This work has supported by the National Research Foundation of Korea (NRF) grant funded by the Korea government(MSIT) (NRF-2020R1F1A1072673 and 2017R1A2B4009376). We also wish to acknowledge the support from Inha University. 


\section{References}

Alshamsi, A., Pinheiro, F.L., Hidalgo, C.A., 2018. Optimal diversification strategies in the networks of related products and of related research areas. Nature communications 9, 1-7.

Bae, Y.H., K.S.J.H., 2016. 2016 corporate rd investments and outcomes. Science and Technology Policy Institute (in Korean) In: Project Reports No. 2016-08-01.

Bahar, D., Hausmann, R., Hidalgo, C.A., 2014. Neighbors and the evolution of the comparative advantage of nations: Evidence of international knowledge diffusion? Journal of International Economics 92,111 123. URL: http://www.sciencedirect.com/science/article/pii/S0022199613001098 doi https:// doi.org/10.1016/j.jinteco.2013.11.001

Balassa, B., 1965. Trade liberalisation and "revealed" comparative advantage 1. The manchester school 33, 99-123.

Balland, P.A., Boschma, R., Crespo, J., Rigby, D.L., 2019. Smart specialization policy in the european union: relatedness, knowledge complexity and regional diversification. Regional Studies 53, 1252 1268. URL: https://doi.org/10.1080/00343404.2018.1437900 doi 10.1080/00343404.2018.1437900 arXiv:https://doi.org/10.1080/00343404.2018.1437900

Boschma, R., 2017. Relatedness as driver of regional diversification: A research agenda. Regional Studies 51, 351-364

Boschma, R., Balland, P.A., Kogler, D.F., 2014. Relatedness and technological change in cities: the rise and fall of technological knowledge in US metropolitan areas from 1981 to 2010. Industrial and Corporate Change 24, 223-250. URL: https://doi.org/10.1093/icc/dtu012 doi 10.1093/icc/dtu012 arXiv:https://academic.oup.com/icc/article-pdf/24/1/223/2481914/dtu012.pdf

Boschma, R., Iammarino, S., 2009. Related variety, trade linkages, and regional growth in italy. Economic Geography $85,289-311$.

Boschma, R., Minondo, A., Navarro, M., 2012. Related variety and regional growth in spain. Papers in Regional Science $91,241-256$

Breschi, S., Lissoni, F., Malerba, F., 2003. Knowledge-relatedness in firm technological diversification. Research Policy 32, 69 - 87. URL: http://www.sciencedirect.com/science/article/pii/S0048733302000045 doi https://doi.org/10.1016/S0048-7333(02)00004-5

Collins, H., 2010. Tacit and Explicit Knowledge. Chicago: University of Chicago Press.

Delgado, M., Porter, M.E., Stern, S., 2016. Defining clusters of related industries. Journal of Economic Geography 16, $1-38$

Frenken, K., Van Oort, F., Verburg, T., 2007. Related variety, unrelated variety and regional economic growth. Regional Studies 41, 685-697.

Gao, J., Jun, B., Pentland, A.S., Zhou, T., Hidalgo, C.A., 2017. Collective learning in china's regional economic development. arXiv: 1703.01369

Granovetter, M., 1985. Economic action and social structure: The problem of embeddedness. American journal of sociology 91, 481-510.

Hall, B.H., Jaffe, A.B., Trajtenberg, M., 2001. The NBER Patent Citation Data File: Lessons, Insights and Methodological Tools. Working Paper 8498. National Bureau of Economic Research. URL: http://www.nber.org/papers/ w8498 doi $10.3386 /$ w8498

He, Z.L., Tong, T.W., Zhang, Y., He, W., 2018. Constructing a chinese patent database of listed firms 
in china: Descriptions, lessons, and insights. Journal of Economics \& Management Strategy 27, 579606. URL: https://onlinelibrary.wiley.com/doi/abs/10.1111/jems.12186 doi https://doi.org/ 10.1111/jems.12186 arXiv:https://onlinelibrary.wiley.com/doi/pdf/10.1111/jems.12186

Hidalgo, C.A., 2021. Economic complexity theory and applications. Nature Reviews Physics URL: https://doi. org/10.1038/s42254-020-00275-1 doi 10.1038/s42254-020-00275-1

Hidalgo, C.A., Balland, P.A., Boschma, R., Delgado, M., Feldman, M., Frenken, K., Glaeser, E., He, C., Kogler, D.F., Morrison, A., Neffke, F., Rigby, D., Stern, S., Zheng, S., Zhu, S., 2018. The principle of relatedness, in: Morales, A.J., Gershenson, C., Braha, D., Minai, A.A., Bar-Yam, Y. (Eds.), Unifying Themes in Complex Systems IX, Springer International Publishing, Cham. pp. 451-457.

Hidalgo, C.A., Klinger, B., Barabási, A.L., Hausmann, R., 2007. The product space conditions the development of nations. Science 317, 482-487. URL: https://science.sciencemag.org/content/317/5837/482 doi 10. 1126/science.1144581 arXiv:https://science.sciencemag.org/content/317/5837/482.full.pdf

Jaffe, A.B., 1986. Technological opportunity and spillovers of r\&d: Evidence from firms' patents, profits, and market value. American Economic Review 76, 984-1001. URL: https://ideas.repec.org/a/aea/aecrev/ v76y1986i5p984-1001.html

Jara-Figueroa, C., Jun, B., Glaeser, E.L., Hidalgo, C.A., 2018. The role of industry-specific, occupation-specific, and location-specific knowledge in the growth and survival of new firms. Proceedings of the National Academy of Sciences $115,12646-12653$.

Julius, T., De Rassenfosse, G., 2014. Harmonising and matching ipr holders at ip australia .

Jun, B., Alshamsi, A., Gao, J., Hidalgo, C., 2017. Relatedness, knowledge diffusion, and the evolution of bilateral trade. SSRN Electronic Journal doi $10.2139 /$ ssrn. 3037720

Kang, B., Tarasconi, G., 2016. Patstat revisited: Suggestions for better usage. World patent information 46, 56-63.

Kang, T., Baek, C., Lee, J.D., 2019. Effects of knowledge accumulation strategies through experience and experimentation on firm growth. Technological Forecasting and Social Change 144, 169-181. doi 10.1016/j.techfore. 2019.04 .003

Kim, J., Lee, C.Y., Cho, Y., 2016. Technological diversification, core-technology competence, and firm growth. Research Policy 45, 113 - 124. URL: http://www.sciencedirect.com/science/article/pii/S0048733315001183 doi https://doi.org/10.1016/j.respol.2015.07.005

Kogler, D.F., Rigby, D.L., Tucker, I., 2013. Mapping knowledge space and technological relatedness in us cities. European Planning Studies 21, 1374-1391. URL: https://doi.org/10.1080/09654313.2012.755832 doi 10. 1080/09654313.2012.755832 arXiv:https://doi.org/10.1080/09654313.2012.755832

Lee, J., Lim, H., Kim, S., Song, K., Jung, J.Y., 2019. (korea patent data project (kopdp): Contents and methods). Available at SSRN 3404698 .

Muneepeerakul, R., Lobo, J., Shutters, S.T., Goméz-Liévano, A., Qubbaj, M.R., 2013. Urban economies and occupation space: Can they get "there" from "here"? PLOS ONE 8, 1-8. URL: https://doi.org/10.1371/journal.pone. 0073676 doi $10.1371 /$ journal.pone.0073676

Neffke, F., Henning, M., Boschma, R., 2011. How do regions diversify over time? industry relatedness and the development of new growth paths in regions. Economic Geography 87, 237-265. URL: https://www.tandfonline. com/doi/abs/10.1111/j.1944-8287.2011.01121.x doi 10.1111/j.1944-8287.2011.01121.x 
arXiv:https://www.tandfonline.com/doi/pdf/10.1111/j.1944-8287.2011.01121.x

Nelson, R.R., Winter, S.G., 1982. An Evolutionary Theory of Economic Change. Cambridge: Harvard University Press Polanyi, M., 1958. Personal Knowledge, Towards a Post Critical Epistemology. Chicago: University of Chicago Press. Powell, W.W., 1990. Neither market nor hierarchy. Research in Organizational Behavior 12, 295-336.

Rigby, D.L., 2015. Technological relatedness and knowledge space: Entry and exit of us cities from patent classes. Regional Studies 49, 1922-1937. URL: https://doi.org/10.1080/00343404.2013.854878 doi 10.1080/ 00343404.2013 .854878 arXiv:https://doi.org/10.1080/00343404.2013.854878

Saxenian, A., 1996. Regional Advantage: Culture and Competition in Silicon Valley and Route 128. Cambridge: Harvard University Press.

Teece, D.J., 1980. Economies of scope and the scope of the enterprise. Journal of Economic Behavior \& Organization $1,223-247$.

Teece, D.J., 1982. Towards an economic theory of the multiproduct firm. Journal of Economic Behavior \& Organization 3, 39-63.

Teece, D.J., Pisano, G., 1994. The dynamic capabilities of firms: An introduction. Industrial and Corporate Change 3 , $537-556$

Teece, D.J., Rumelt, R., Dosi, G., Winter, S., 1994. Understanding corporate coherence: Theory and evidence. Journal of Economic Behavior \& Organization 23, 1-30.

Thoma, G., Torrisi, S., et al., 2007. Creating powerful indicators for innovation studies with approximate matching algorithms: a test based on PATSTAT and Amadeus databases. Università commerciale Luigi Bocconi. 
A

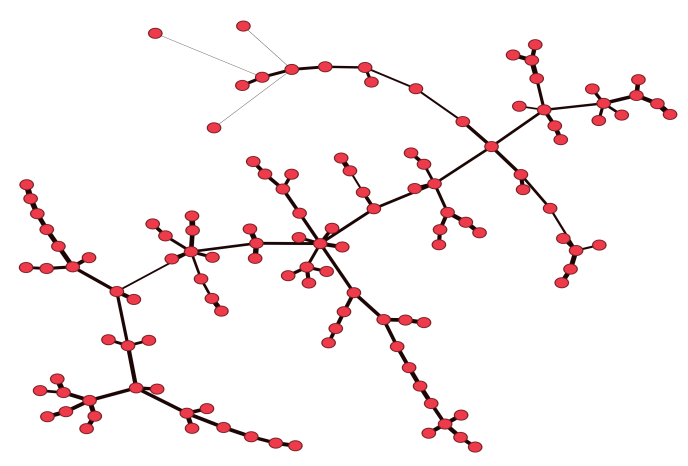

C

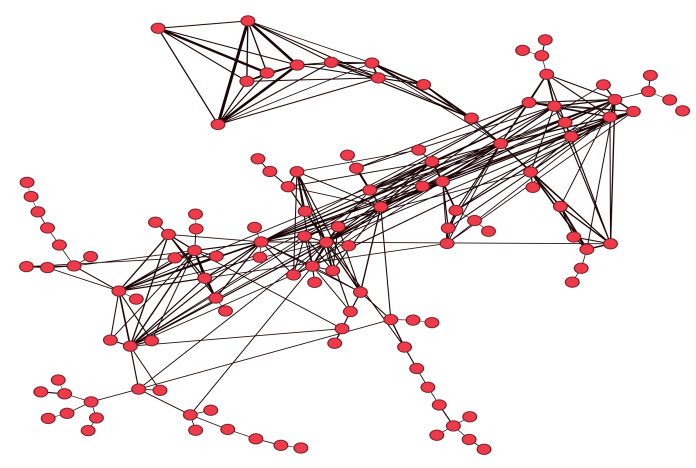

B

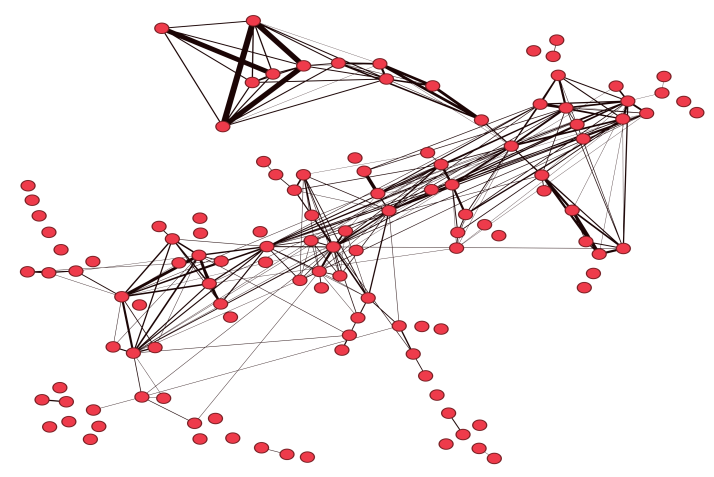

D

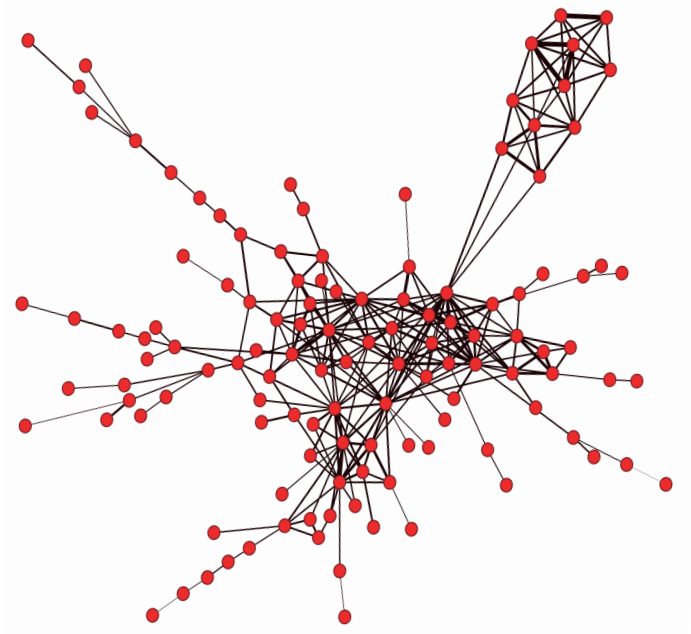

Figure A1: Process of constructing the technology space

To construct a representative technology space, patents from 2004 to 2014 are aggregated to generalize the relationship between two different technologies. If not, the annual trend of a certain technology section could be highlighted. After calculating the proximity, $\phi_{\alpha, \beta}$ in Eq. 1 we build a proximity matrix $\Phi$ for all pairs of technologies that have a three-digit IPC level whose sub-sectoral number is 131 . To visualize the representative technology space, we follow 
the methodology of Gao et al. (2017). The first step is to build a maximum spanning network that connects all the nodes with the minimum number of links, as shown in Figure A1, A. The result includes 121 links connecting 122 nodes that maximize total proximity and ensure connectivity.

The second step is to build a maximum weighted network with links whose proximity is above a certain threshold value, $\phi^{\prime}$. We set $\phi^{\prime}$ as 0.4 , meaning that another network consisting of 258 links with 85 nodes is created, as shown in Figure A1, B.

In the third step, we combine the above two networks to create a superposed network comprising 122 nodes with 300 links, as depicted in Figure A1, C. To improve the visualization, we use the ForceAtlas2 algorithm of Gephi (http://gephi.github.io) to locate the node with the better place to minimize the number of overlapping links and untangle dense clusters. Figure A1. D illustrates the final composition of the technology space. Lastly, we add color to the nodes to distinguish the IPC category at the one-digit level. The thickness and its color represent the link weight. The final output is Figure 2 (A).
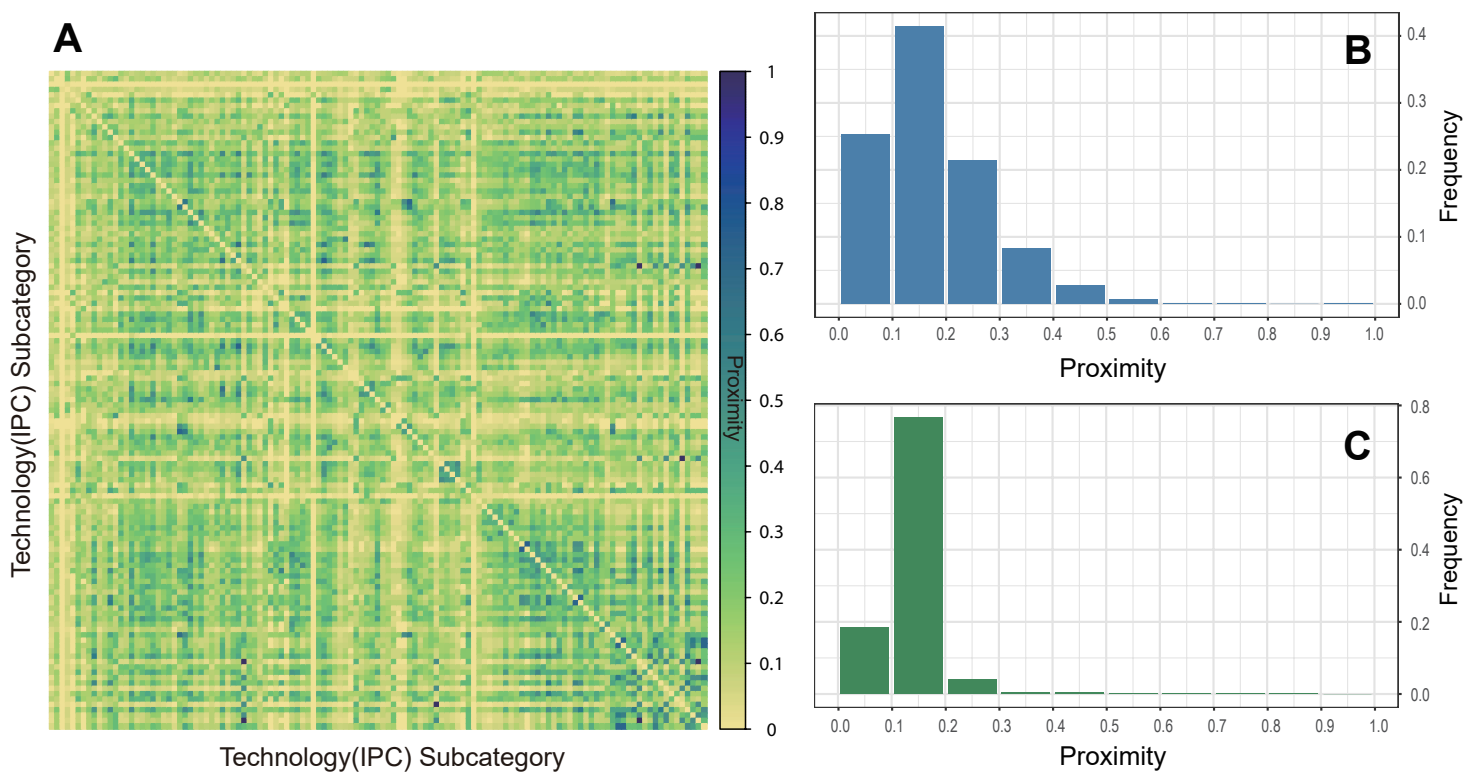

Figure A2: (A) Hierarchically clustered matrix of $\Phi$, (B) The distribution of all the proximities, $\Phi$, and (C) The distribu-

tion of $\phi$ after conducting the above-described four steps

The hierarchically clustered matrix in Figure A2 (A) shows the colored matrix for all the proximities, $\Phi$, of every pairwise IPC relationship. Figure A2 (B) and (C) shows this distribution graphically. When we consider all the pairwise relationships of two technologies $\left({ }^{122} C_{2}\right)$, its frequency appears as a log-normal distribution. We can check that the shape of the distribution of 300 links after carrying out the four steps above(i.e., only those proximity values used to construct the technology space) is not changed substantially. 
Figure 2 (A) shows the technology space of the Korean manufacturing industry for 20042014. In agreement with previous findings on the product space and industry space (Hidalgo et al. 2007, Gao et al., 2017), even in the technology space, we can also find similar results for less complicated technologies. As such, the IPC codes of Textiles, Paper (D), Fixed Constructions (E), and Human necessities (A) are located at the periphery of the technology space.

The general characteristics of the network are as follows. The node with the highest degree (i.e., the most connected node) is $\mathrm{H} 02$ called "Generation, Conversion, or Distribution Of Electric Power" in electricity (H). The links with the highest weight are B33-G06-H04 and C9-H01. The names of these IPC codes are (B33) Additive Manufacturing Technology; (C99) Subject Matter Not Otherwise Provided For In Chemistry/Metallurgy; (G06) Computing; Calculating; Counting; (H01) Basic Electric Elements; and (H04) Electric Communication Technique.

However, in the technology space at the firm level, we find a unique feature not available at the country or industry level. We can classify the whole into a continent and an island. At 11 o'clock, we identify a cluster that mainly consists of physics $(\mathrm{G})$ and electricity $(\mathrm{H})$. Both links with the highest weight mentioned above (B33-G06-H04 and C99-H01) are located on this island. These technologies are related to home electronic appliances, displays, and semiconductors, which are the main products of Korea's manufacturing industry.

One concept suggested by Hidalgo et al. (2007) is ubiquity, or how many countries can produce a certain product. If the ubiquity of a product is low, only few countries can produce it (In other words, the product with low ubiquity is hard to produce). In the product space, those products positioned at the center have low ubiquity, and consequentially only a few countries occupy that space. However, in the technology space, complicated technologies (nodes) that have low ubiquity are found on the island (tied with the highest weighted links). This difference can be interpreted as follows. The countries that can produce complex products also have the capability to produce less complex products. However, firms that possess more advanced capability that can produce complicated products with sophisticated technologies do not necessarily possess the unsophisticated technologies needed to produce simple products. In other words, a firm only develops the knowledge necessary to create the products confined to their specialty. As we see at Figures 2 (B)-(D), technologies mainly consisting of the island of the technology space are occupied by certain firms (in this case, Samsung Electronics) and it means that the technologies owned by firms are localized compared with at the country level. 


\section{Appendix B. Correlation table}

Table A1: Correlation matrix (1984-2014)

\begin{tabular}{lcccccc}
\hline \hline & $\omega_{i, \alpha, t}$ & Industry $_{\alpha, t}$ & Age $_{i, t}$ & Sales $_{i, t}$ & Profit $_{i, t}$ & Debt $_{i, t}$ \\
\hline$\omega_{i, \alpha, t}$ & 1 & & & & & \\
Industry $_{\alpha, t}$ & 0.144 & 1 & & & & \\
Age $_{i, t}$ & 0.121 & 0.011 & 1 & & & \\
Sales $_{i, t}$ & 0.390 & 0.011 & 0.528 & 1 & & \\
Profit $_{i, t}$ & -0.105 & -0.021 & -0.138 & -0.266 & 1 & \\
Debt $_{i, t}$ & 0.057 & -0.138 & 0.0005 & 0.067 & -0.213 & 1 \\
\hline & & & & & & \\
\hline
\end{tabular}

